\title{
E-commerce Applications based on SaaS For MSMEs in Kudus District
}

\author{
Supriyono $^{1}$, Andy Prasetyo Utomo ${ }^{2}$, Muhammad Arifin $^{3}$, Fajar Nugraha ${ }^{4}$ \\ \{supriyono.si@umk.ac.id ${ }^{1}$, andy.prasetyo@umk.ac.id², arifin.m@umk.ac.id ${ }^{3}$ \}
}

Universitas Muria Kudus, Gondangmanis Bae Kudus Jawa Tengah, 02914382291234

\begin{abstract}
Kudus is one of the districts in Indonesia. In Kudus there are many SMEs. One of the main problems facing by SMEs in Kudus districts is the limited marketing network. Although to overcome the limitations of the range of marketing can be done by utilizing Information Technology (IT) such as by using E-Commerce. But the use and application of IT in SMEs has constraints that lack of funding for infrastructure procurement and lack of manpower with sufficient knowledge and skills to manage IT infrastructure. In applying SaaS application software concept into E-Commerce applications, this research uses object-oriented system development methods with UML tools. The E-Commerce category used is B2C. The purpose of this study is to produce cloud computing-based E-Commerce applications that can help SMEs in Kudus districts to expand their market share. The results of this study are E-Commerce application software for SMEs based on SaaS Cloud Computing.
\end{abstract}

Keywords: SME, e-commerce, SaaS cloud computing.

\section{Introduction}

The economic growth of a country is influenced by many factors, one of which is the existence of SMEs. SMEs have an important role in national economic development by creating more jobs for the wider community. In an effort to further develop SMEs, government and community attention needs to be more devoted to boosting self-sufficiency, success and increased competitiveness of SMEs with other economic actors.

Kudus is one of the districts in Indonesia located in central java province. Industry and trade are the main supporting sectors of the economy in Kudus district. In addition to large scale industries, there are also many SMEs in Kudus district. Up to 2017, there are more than 13,600 SME units in Kudus regency consisting of various types of businesses, such as convection, batik, embroidery, bags, shoes, processed foods, soy sauce, syrup, knives, dolls, spare parts and others etc.

One of the main problems faced by SMEs, especially in Kudus district is the limited marketing network. With the ability of production that has been qualified but the limited market will be hindered the survival of SMEs. Therefore, steps needed to overcome the marketing problems of SMEs production. Actually, the government of Kudus district through the Department of Industry, Cooperatives and SME has held several activities to expand the marketing network of SMEs in Kudus among others by organizing Regional Crafts Exhibition. However, these activities can only reach the regional market has not reached the national and international scale.

ICCSET 2018, October 25-26, Kudus, Indonesia

Copyright (C) 2018 EAI

DOI 10.4108/eai.24-10-2018.2280632 
In order to overcome the limited reach of marketing, SMEs are required to make changes and increase competitiveness, one of them by utilizing Information Technology. The use of IT can improve business transformation through the speed, accuracy and efficiency of exchanging large amounts of information. One of the utilization of IT in overcoming the limitations of marketing range is by using E-Commerce. E-Commerce, is trading in products or services using computer networks, such as the Internet. Electronic commerce draws on technologies such as mobile commerce, electronic funds transfer, supply chain management, Internet marketing, online transaction processing, electronic data interchange (EDI), inventory management systems, and automated data collection systems [1].

Indonesia has a very large number of internet users, by 2016 according to a survey conducted by the Association of Indonesian Internet Network Providers (APJII), indicating that 132.7 million Indonesians are connected to the internet. Based on data released by the Ministry of Communications and Informatics shows that the value of online transactions in Indonesia during 2016 is estimated to reach US \$ 4.89 billion, or equivalent to Rp. 68 trillion. The number of online transactions is also very large followed by the large number of consumers who transact through E-Commerce. As of December 2016 the number of consumers in Indonesia who transacted in online stores reached 9.7 million consumers.

Although E-Commerce users can bring many benefits and successes in particular to increase sales turnover and marketing coverage for SMEs, but the use and application of IT in SMEs is not as easy as imagined because there are some obstacles. The main obstacles faced by SMEs in using IT is the lack of funds to procure IT infrastructure and labor shortages that have the knowledge and skills necessary to manage the IT infrastructure [2].

A key factor in ensuring the sustainability and quality of IT services is the availability of adequate IT resources. Procurement of IT resources will be followed by the availability of funds because the cost factor will always be directly proportional to the procurement of resources. Cloud computing is a new paradigm in the IT world. Cloud computing can be used to help resolve IT resource procurement issues. One characteristic of cloud computing is a usage-based rental. With cloud computing, SMEs can implement IT without having to procure IT resources first.

Cloud computing has multiple layers of service. One of the services directly related to ECommerce is SaaS (Software as a Service). With SaaS, the software can be directly used by the user without the need for stages of development, configuration or installation. The fee payable by software users as long as the user still uses the software is calculated based on the time, data quota, transaction amount or other payment type options offered by SaaS Cloud service providers. All matters related to the use of software which includes hardware, software maintenance, data backup, security and so on, are the responsibility of the service provider. Saas is a new paradigm in the financing and the use of information technology resources [3].

By using the SaaS concept, the user as a software user can directly use and utilize the software without having to spend the cost of development or procurement first. In addition, users also only pay the rent during the still using the software. In terms of hardware used to support the running of software, users do not need to think about the cost of procurement and maintenance, because all have been borne by the vendor or cloud service provider. 


\section{Research Method}

Stages performed in the study, shown in Figure 1. In the first stage of data collection. In this first stage, the first activity is observation. Observations were made through the observation and recording of marketing management problems facing SMEs in Kudus district. In addition, also conducted interviews to be able to dig deeper on the real problems that exist in the field. The second activity in this data collection phase is literature study. Activities undertaken are finding and studying theories that can be used as the foundation of the theory or framework in research. Some of the things studied include SaaS Cloud Computing theory, a research journal that discusses SaaS Cloud Computing, a research journal that discusses the concept of marketing management and E-Commerce management, research journals that discuss the development of systems, and so forth. The main objective of the second activity of this first stage is to find the appropriate methodology and compare the theory with the facts in the field.

The second stage in this study is the analysis and identification of research needs. The first activity in this stage is to analyze and identify problems based on data already collected at the first stage. After doing the problem analysis followed by the second activity is to perform the needs analysis. In this activity, several activities are done to identify the need for automation to further increase the range of marketing, to provide proposed technology alternatives to market SME products, to evaluate the feasibility of the system from several proposed alternatives, to establish a choice of proposed technology alternatives that will be Developed to realize the expansion of SME product marketing range

The third phase of this research is conducting the design of the research execution. The first activity of this stage is generating system analysis, the activities undertaken in this activity is to determine the methods and tools to perform system design, the second activity in this stage is the conceptual design system, the activities undertaken in this activity is to make the system design that poured in the form Graphical notation using system design tools that have been determined in the previous activity. The third activity in this stage is the detail system design, the activities undertaken in this activity is to make the database design and interface of the system to be developed.

The fourth phase of this research is Research Implementation. The first activity of this stage is to develop the design results that have been done in the previous stages into an application prototype. The resulting application prototype is then applied or tested to the user or research partner. The second activity of this stage is to implement the infrastructure needed to run the applications that have been developed. The infrastructure intended here consists of hardware, software and users who have qualified in running the system that has been developed. 


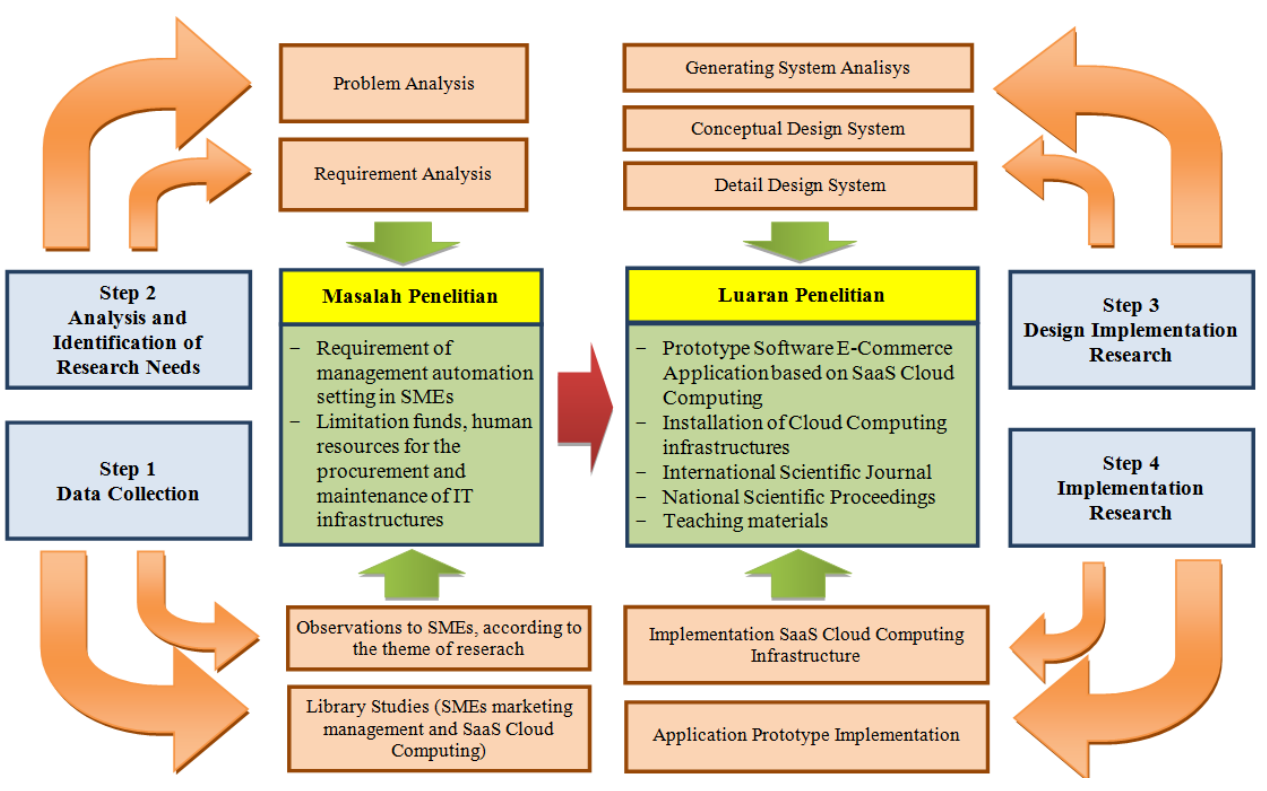

Fig. 1. Research Stages.

\section{Results and Analysis}

In implementing Cloud Computing services, it is necessary to act as a service provider. A cloud service provider is an organization or company that has the infrastructure or IT resources and then shares its IT resources to cloud users for a fee. Cloud E-Commerce applications generated in this research will be applied in Department of Industry, Cooperative and SME in Kudus District, As the party responsible for the development of SMEs in Kudus district. Department of Industry, Cooperative and SME in Kudus district here serve as a provider of cloud services. While the role as a cloud user is SMEs in Kudus district. SMEs can access the cloud services provided by Department of Industry, Cooperative and SME in Kudus district through internet connection using various media such as smart phones, laptops, PCs, tablets and others. The distribution of cloud services provided by Department of Industry, Cooperative and SME in Kudus district to SMEs in Kudus district is shown in Figure 2. 


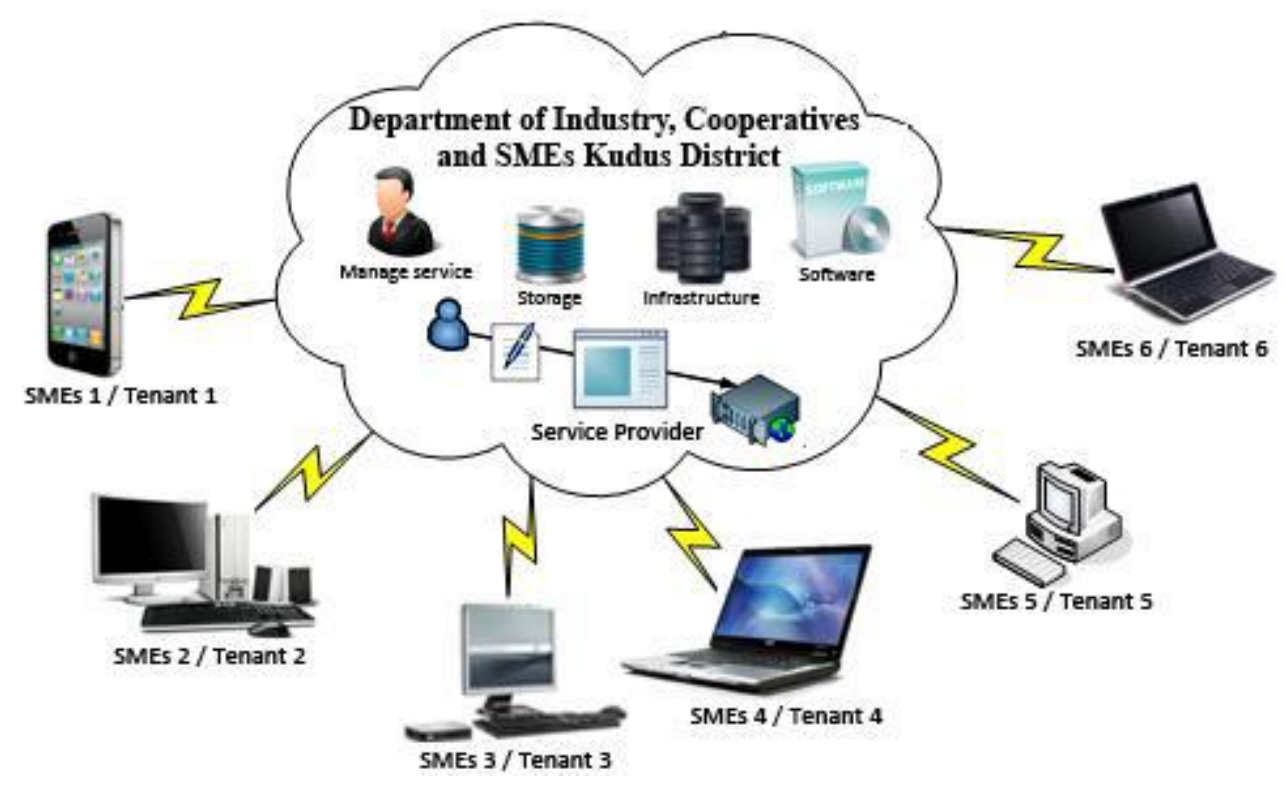

Fig. 2. Distribution of Cloud Computing Services in Kudus District [4].

The E-Commerce category applied to the SaaS E-Commerce application is B2C (Business-To-Consumer). B2C is a Business or transaction conducted directly between the company and the consumer who is the end user of the product or service [1]. In this ECommerce category, the producers market and sell products and services directly to consumers. Consumers only act as users or buyers of products. Consumers can not provide feedback or do business back to the producers. Classification of B2C E-Commerce model applied in this research is Online Store. Online Store is a place to sell or buy digitally by choosing, ordering goods via the internet without having to face to face with the seller directly or the goods you want to buy. The B2C E-Commerce model is shown in Figure 3.

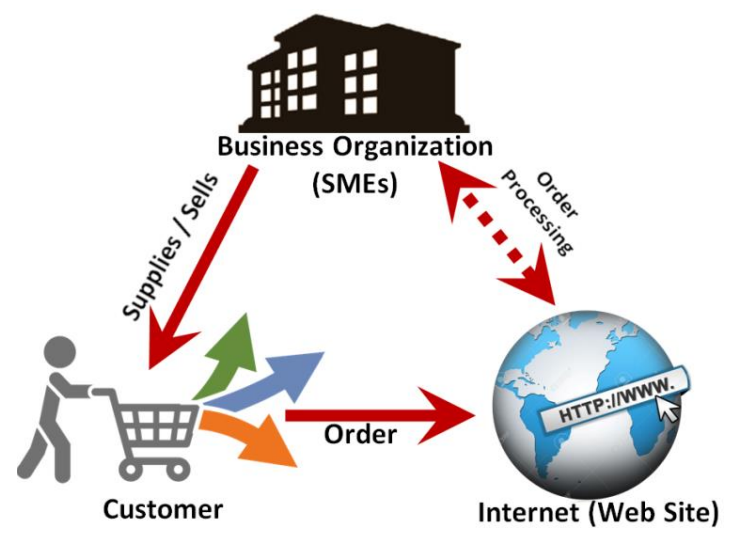

Fig. 3. E-Commerce B2C Model. 
The SaaS Cloud Computing service uses the Multi-tenant architecture. Every SaaS cloud computing customer is called Tenant. Multi-tenant architecture runs the application on the infrastructure of the service vendor, and multiple tenants are then allowed to access the same instance of the application with customized configurations [5]. By using multi-tenant architecture an application will be used by many tenants at once.

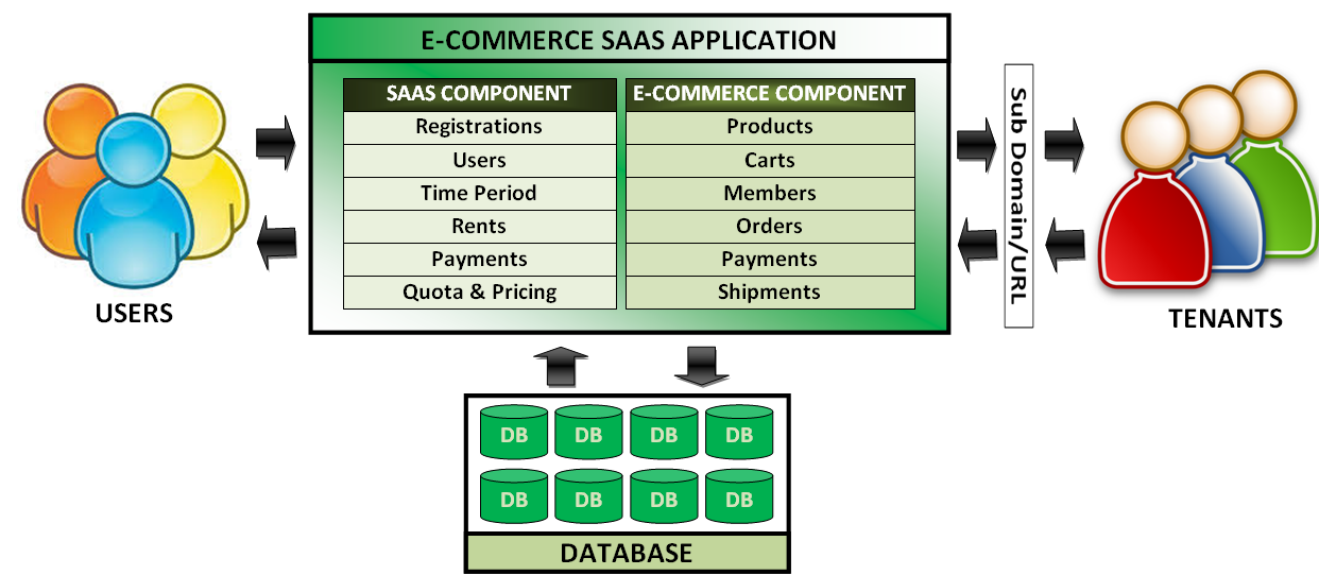

Fig. 4. SaaS E-Commerce Multitenant Architecture model.

Multi-tenant is meet lots of enterprises to share one application instance in which each user can only access data belonging to his tenant [6]. Although in the Muti-tenant architecture, each tenant accesses the same application, but the data accessed only data owned by the tenant. There are various methods in the multitenant architecture associated with data storage and access. In this study the method used is a separate database method. In a separate database method each tenant will have its own database to store its data. This method has the advantage of data security, although in terms of efficient use of data storage is less. Figure 4 shows the SaaS E-Commerce Multitenant Architecture model used in this research, where providers and tenants as application users will be able to use SaaS components, while Tenant and ECommerce application users will access applications through their chosen SubDomain when renting an application. The Saas and E-Commerce components will access the database. Each tenant will store and access data that is in their own database.

The SaaS-based E-Commerce application developed consists of four actors, namely Administrators, SME owners, SME operators, and Customers. Administrators are IT staff present in the Department of Industry, Cooperative and SME Kudus who are appointed as managers of SaaS Ecoomerce applications. Owners of SMEs are SME managers, SME operators are SME employees who are in charge of operating E-Commerce applications and Customers are Potential Buyers or the general public that Product offered by SMEs through ECommerce Application. A detailed description of what each actor does in the application is embedded in the application design in the usecase diagram shown in Figure 5. Usecase is the specification of a set of actions executed by the system [7]. 


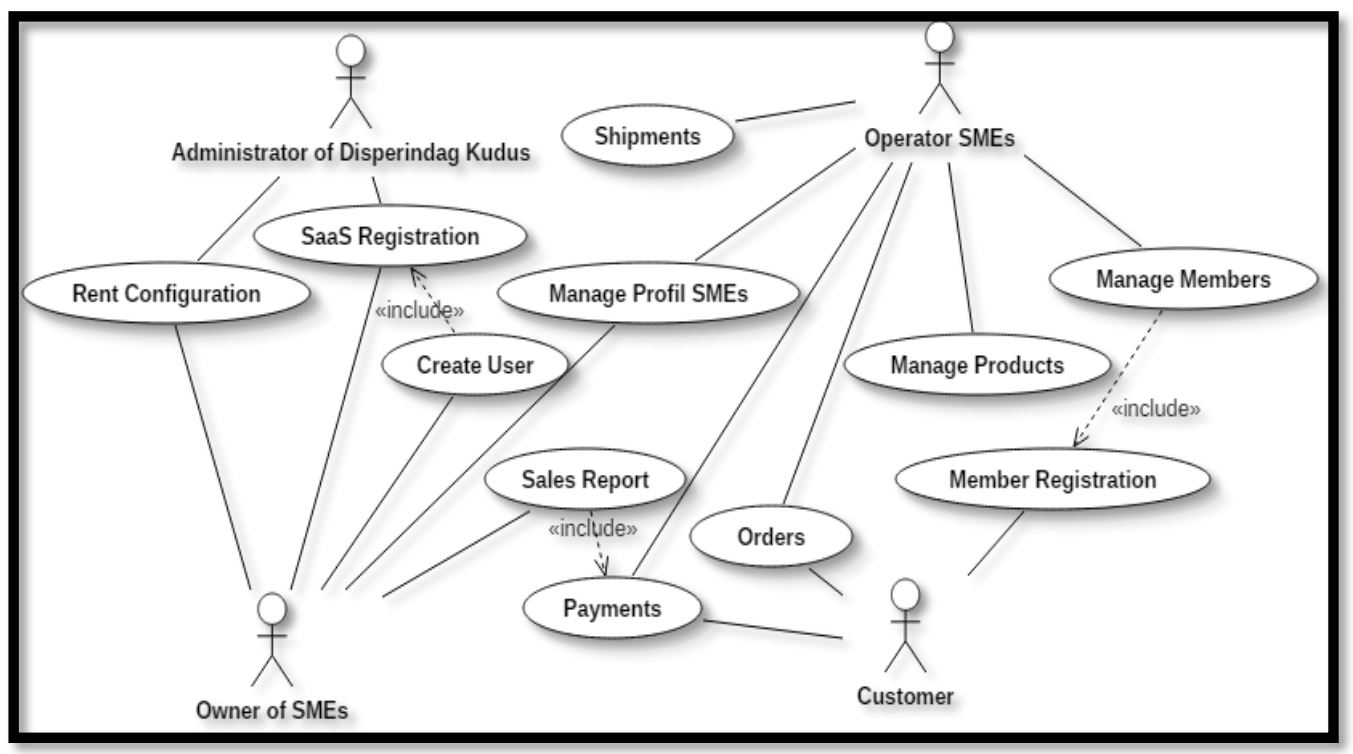

Fig. 5. Use Case Diagram of SaaS E-Commerce Application.

\section{Conclusion}

The absence of sufficient funds in the procurement of IT resources is a constraint faced by SMEs in Kudus District. These constraints can be overcome by using SaaS Cloud computing services. SaaS service Cloud computing will be provided by Department of Industry, Cooperatives and SME in Kudus district. By using Cloud Computing SaaS Services in the form of E-Commerce applications, SMEs can expand market share without thinking of the procurement process, installation and configuration of hardware or software. The SaaS Cloud Computing E-Commerce application can also be directly used by many SMEs in Kudus district.

\section{References}

[1] S. Shahriari, M. Shahriari, and S. Gheiji, "E-Commerce and It Impacts on Global Trend and Market,” Int. J. Res. -Granthaalayah, vol. 3, no. 4, pp. 49-55, 2015.

[2] H. Hairuddin, N. L. M. Noor, and A. M. A. Malik, "Why do Microenterprise Refuse to Use Information Technology: A Case of Batik Microenterprises in Malaysia," Procedia - Soc. Behav. Sci., vol. 57, no. June 2014, pp. 494-502, 2012.

[3] D. C. Wyld, "The Utility Of Cloud Computing As A New Pricing - And Consumption - Model For Information Technology," Int. J. Database Manag. Syst., vol. 1, no. 1, pp. 1-20, 2009.

[4] Supriyono and A. Prasetyo Utomo, "Utilization Of Saas (Software As A Service) Cloud Computing On Financial Management Applications Smes In Kudus District," J. Educ. Soc. Sci., vol. 4, pp. 319-323, 2016. 
[5] S. K. Khatri, H. Singhal, and K. Bahri, "Multi-Tenant Engineering Architecture in SaaS," Int. J. Comput. Appl., pp. 45-49, 2013.

[6] Y. Zhu, "A Platform For Changing Legacy Application To Multi-Tenant Model," Int. J. Multimed. Ubiquitous Eng., vol. 9, no. 8, pp. 407-418, 2014.

[7] N. Ibrahim, R. Ibrahim, M. Z. Saringat, D. Mansor, and T. Herawan, "Consistency Rules between UML Use Case and Activity Diagrams Using Logical Approach," Int. J. Softw. Eng. Its Appl., vol. 5, no. 3, pp. 498-508, 2011. 